\title{
Elongation gastroplasty with transverse fundoplasty: The Jeyasingham repair
}

Xavier Benoit D’Journo, MD, Jocelyne Martin, MD, Soufiane Bensaidane, MD, Pasquale Ferraro, MD, and André Duranceau, MD

Objective: Surgical management of massive hernias and complex gastroesophageal reflux disease requires a tension-free repair with reliable reflux control. The aim of this observation was to evaluate the functional results of a modified Collis-Nissen gastroplasty with a transverse widening fundoplasty.

Methods: Between 1995 and 2007, 26 patients underwent a 3-cm cut elongation gastroplasty with a transverse widening of the fundus followed by a $3-\mathrm{cm}$ total $(\mathrm{n}=24)$ or partial $(\mathrm{n}=2)$ fundoplication. Indications for the operation were symptomatic massive hiatal hernias $(n=4)$, hiatal hernias with Barrett's esophagus $(n=8)$, or correction of previously failed antireflux fundoplications $(n=14)$. Barrett's esophagus was documented in 19 of the 26 patients. Pre- and postoperative assessment included symptoms, barium swallow, endoscopy, manometry, and 24-hour $\mathrm{pH}$ monitoring.

Results: There was no postoperative mortality. Complications were recorded in 6 patients. Median follow-up was 105 months. Reflux symptoms present in all patients before the operation were found in 5 patients postoperatively $(P<.001)$. Radiologic assessment documented an intact fundoplication in all patients. Lower esophageal sphincter gradient increased from a mean of 7.5 to $15 \mathrm{~mm} \mathrm{Hg}(P=.003)$. Acid exposure (17\% preoperatively) decreased significantly to $1 \%$ postoperatively $(P<.001)$. Endoscopically, mucosal damage quantification decreased $(3.1$ preoperatively to 1.5 postoperatively; $P<.001)$. All mucosal breaks healed but the columnar-lined metaplasia persisted.

Conclusions: This modified elongation gastroplasty provided a reliable repair for massive hernias, shortened Barrett's esophagus, and reoperations. The lower esophageal sphincter gradient was restored and remained stable. Reflux exposure was reduced, and acute mucosal damage disappeared. Columnar-lined metaplasia remained unchanged.

The esophagus is considered shortened in patients with massive hernias, reflux stricture, and extensive columnar-lined metaplasia and when reflux damage persists despite previous repairs. ${ }^{1}$ Collis $^{2}$ in 1957 tackled the problem by creating a simple elongation gastroplasty with anterior closure of the hiatus. Pearson and colleagues ${ }^{3}$ in 1971 suggested adding a Belsey-type partial fundoplication to the gastroplasty. The high prevalence of persistent reflux led others to add a total fundoplication to the cut gastroplasty. ${ }^{4-6}$ In parallel, a stapled uncut gastroplasty was also proposed by Bingham, ${ }^{7,8}$ Demos and colleagues, ${ }^{9,10}$ and subsequently Evangelist and associates ${ }^{11}$ and Paris and coworkers. ${ }^{12}$ The long-term results of these operations have been reported, suggesting good control

\footnotetext{
From the Department of Surgery, Université de Montréal, Division of Thoracic Surgery, Centre Hospitalier de l'Université de Montréal, Montréal, Québec, Canada.

Supported by La Fondation de France (Paris) and by the Thoracic Surgery Research Foundation of Montreal.

Received for publication July 23, 2008; revisions received Oct 7, 2008; accepted for publication Nov 2, 2008; available ahead of print June 1, 2009.

Address for reprints: André Duranceau, MD, Division of Thoracic Surgery, Centre Hospitalier de l'Université de Montreal, Pavillon Lachapelle, Suite D-8051, 1560 rue Sherbrooke Est, Montreal, Québec, Canada H2L 4M1 (E-mail: andre. duranceau@umontreal.ca).

J Thorac Cardiovasc Surg 2009; 138:1192-9

$0022-5223 / \$ 36.00$

Copyright (c) 2009 by The American Association for Thoracic Surgery doi:10.1016/j.jtcvs.2008.11.067
}

of the hiatus repair; however, persistent acid exposure on the esophageal mucosa occurred in a significant number of patients. ${ }^{13-15}$

In 1984, Reilly and Jeyasingham ${ }^{16}$ proposed a modified gastroplasty, in which the gastric fundus is widened by transverse closure, providing ample fundic tissue for the completion of a partial or a total wrap around the gastroplasty. The operation was intended to allow better reflux control and to avoid the dysphagia and slow emptying observed with the uncut gastroplasty. It also provided healthy tissue around the gastroplasty in patients with failed previous repairs. The long-term outcome reported by Jeyasingham ${ }^{17}$ is excellent with no long-term recurrence, relief of symptoms, and healing of acute esophagitis, especially in patients with previously failed antireflux repairs.

Few reports on this operation have been published recently. The main goal of this study was to review the long-term functional results of the Jeyasingham repair in our cohort of patients.

\section{MATERIAL AND METHODS \\ Patient Population}

The Institutional Review Board of our hospital approved the design of this study. Because of its retrospective nature, the need for patient consent was waived. 


\section{Acronym and Abbreviation}

$$
\text { LES }=\text { lower esophageal sphincter }
$$

Between January 1995 and June 2007, 91 elongation gastroplasties were completed in our Thoracic Surgery Division. Among these patients, 26 underwent a $3-\mathrm{cm}$ cut elongation gastroplasty with a transverse widening of the fundus (Jeyasingham repair) followed by a total $(n=24)$ or partial $(\mathrm{n}=2)$ fundoplication.

The cohort included 15 men and 11 women with a mean age of 55 years (range, 28-71). Clinical characteristics and indications for the operation are summarized in Table 1 . The Jeyasingham repair was used for the correction of recurrences and failed (1 to 3) antireflux fundoplications in 14 patients. In 12 patients, it was used as the primary repair for type III massive hiatal hernias $(n=4)$, for hiatal hernias with circumferential Barrett's esophagus $(n=5)$, and for Barrett's Esophagus with peptic strictures $(n=3)$. A hernia is described as massive when a hydroaeric level is present behind the heart on radiologic examination. Among patients with a massive hiatal hernia, 1 presented with an acute intrathoracic perforation of a recurrent hernia. Of the patients with failed previous antireflux repairs $(\mathrm{n}=14), 11 \mathrm{had}$ an abdominal Nissen fundoplication and 3 had a Collis-Nissen gastroplasty (Table 1). The reasons for failure of previous fundoplications included 8 patients with an intrathoracic migration and 6 who had complete disruption of the valve. Barrett's esophagus was documented preoperatively in 19 of the 26 patients. None of the patients had evidence of primary or secondary esophageal motor disorders. Figure 1 describes the various steps required to perform the repair. The endoscopic effect of the operation is illustrated in Figure 2.

\section{Follow-up}

Patients were assessed clinically at 4 months and 1 year after the repair. After the second year and every 2 years thereafter, clinical and functional assessments were obtained when possible. Patients were assessed for symptoms, radiologic findings, and existing mucosal damage at endoscopy and on biopsies.

\section{Symptom Assessment}

Clinical assessment took place in the outpatient clinic and in the esophageal function laboratory. Five symptom categories were investigated: (1) dysphagia and/or slow emptying, (2) odynophagia, (3) regurgitation, (4) heartburn, and (5) oropharyngeal symptoms including aspirations. All symptoms were recorded as being present or absent, and no effort at quantifying severity was attempted.

\section{Radiologic Evaluation}

Standard barium esophagogram was obtained under fluoroscopic control with 4 to 6 frames printed per second. The presence of a hiatal hernia (types I, II, and III), spontaneous gastroesophageal reflux, and visual evidence of mucosal alteration as stricture or mucosal thickening were recorded. Esophageal stasis, when observed at the end of the examination, was also recorded.

\section{Endoscopy}

A standard fiber-optic system (Olympus, GIF-130; Olympus Canada, Toronto, Ontario, Canada) was used to assess the esophagus and gastroesophageal junction. The MUSE classification of Armstrong and colleagues ${ }^{18}$ was used to report and quantify mucosal damage. Visual mucosal lesions were classified as metaplasia, ulcer, stricture, and erosion. A normal-appearing mucosa without any evidence of mucosal break was given a score of 0 . If metaplasia was suspected, tonguelike changes received a score of 1 , and circumferential metaplasia was scored as 2. Ulcers present at the junction of both mucosa were given a score of 1 but if present within a columnar metapla-
TABLE 1. Indications for the cut elongation gastroplasty and clinical characteristics

\begin{tabular}{lc}
\hline & $\mathbf{n}=\mathbf{2 6}(\mathbf{\%})$ \\
\hline Clinical characteristics & \\
Men/women & $15 / 11$ \\
Age $(\mathrm{y})$ & $55 \pm 12$ \\
Height $(\mathrm{cm})$ & $164 \pm 7$ \\
Weight $(\mathrm{kg})$ & $69.3 \pm 15$ \\
Surgical indications & \\
Primary procedure & $12(46)$ \\
Massive HH (type III) & 4 \\
Circumferential BE \pm HH & 5 \\
Peptic stricture + HH & 3 \\
Redo operation & $14(54)$ \\
Massive HH (type III) & 3 \\
Circumferential BE \pm HH & 11 \\
Previous failed antireflux operation & \\
Previous surgery & \\
Nissen abdominal & 11 \\
Collis-Nissen & 3 \\
Number of previous surgery & \\
1 & 12 \\
2 & 1 \\
3 & 1 \\
\hline Values are expressed in percent or mean and standard deviation. BE, Barrett’s esoph-
\end{tabular}

Values are expressed in percent or mean and standard deviation. $B E$, Barrett's esophagus; $H H$, hiatal hernia.

sia zone they were given a 2. Stricture at the anastomosis if it allowed the passage of the instrument was given a 1. If stricture stopped the instrument's progression, it was reported as a 2. A single mucosal erosion was given a 1, and multiple or circumferential erosions were recorded as 2 . The addition of the score in all 4 types of mucosal damage gave the MUSE score severity (mucosal damage quantification).

\section{Histopathology}

Multiple circumferential biopsies were taken from the distal esophagus and from the mucosal junction above the gastric cavity. All esophageal biopsies underwent hematoxylin and eosin staining to identify mucosal damage and metaplasia. The severity of mucosal damage in the esophageal remnant was classified as for idiopathic reflux disease: inflammation, mucosal breaks (erosion and ulceration), and columnar-lined metaplasia. Barrett's esophagus was defined as intestinal metaplasia (specialized epithelium) on biopsies.

\section{Manometry}

Esophageal motility studies were performed using a 4-lumen perfused system (R4 A 5-5-5; MUI Scientific, Mississauga, Ontario, Canada). Each lumen ended $5 \mathrm{~cm}$ apart, and all were oriented at $90^{\circ}$ to each other. Perfusion was performed at a rate of $0.7 \mathrm{~mL} / \mathrm{min}$ using a low-compliance ArndorferMUl-type pneumohydraulic pump (PIP-3; MUI Scientific) generating $15 \mathrm{psi}$ of pressure. Pressures were recorded on a 4-channel physiograph (Gould) after amplification. Ten swallows of a 2-mL water bolus were recorded in the proximal and distal half of the esophagus. With esophageal resting and peak contraction pressures, the types of contractions (primary peristalsis or tertiary waves) were recorded in the proximal and distal esophagus. Using a station pull-through technique, the lower esophageal sphincter (LES) resting pressure was recorded. Relaxation was termed normal when the relaxation pressure fell within $5 \mathrm{~mm} \mathrm{Hg}$ of resting intragastric pressure. The closing pressure was defined as the peak contraction values of the LES at the end of the relaxation phase. The intragastric pressure was subtracted 

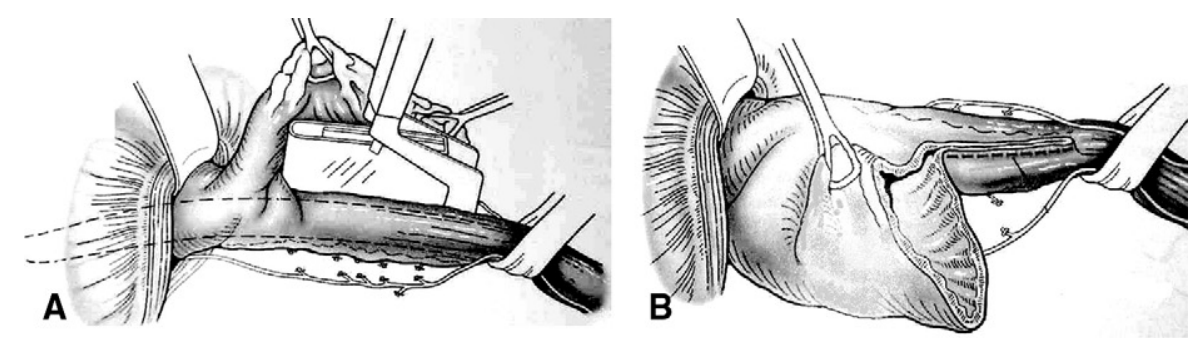

C
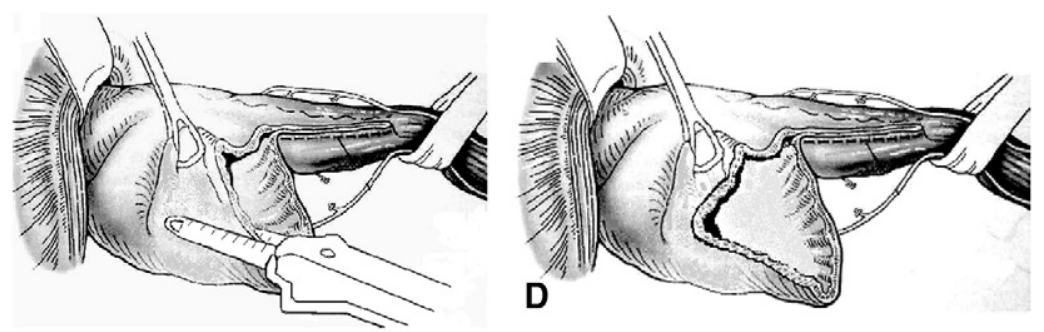

E
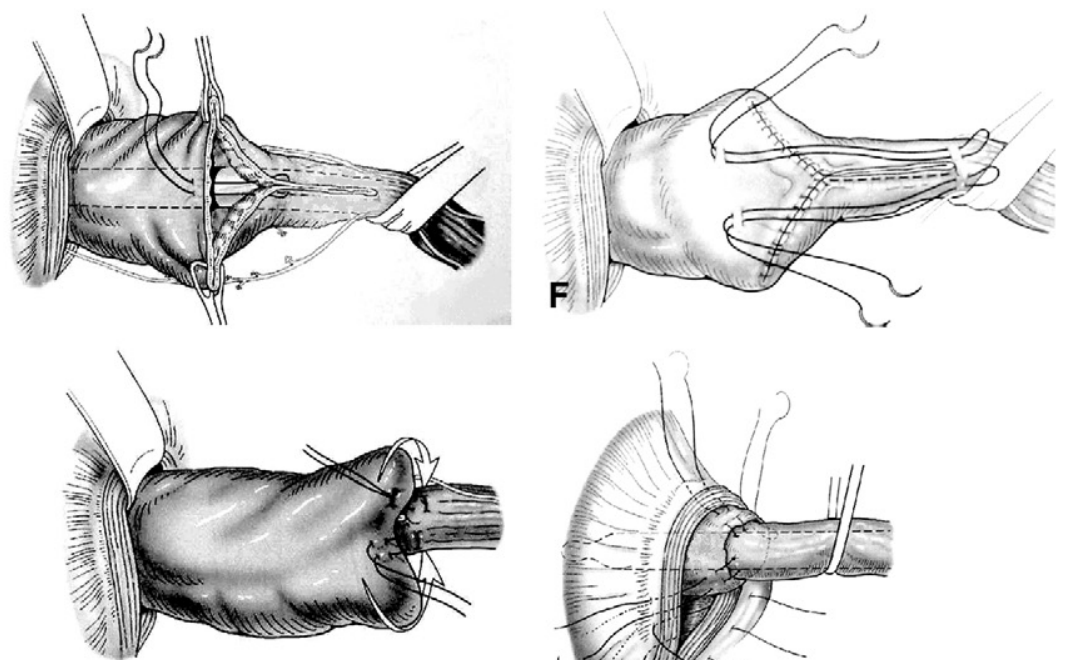

G
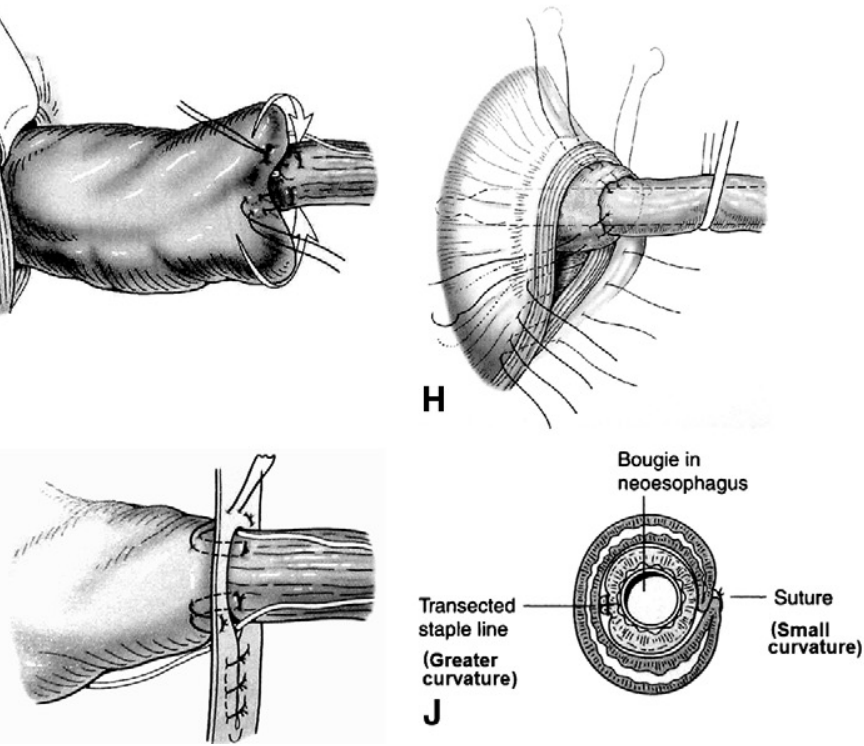

FIGURE 1. Cut elongation gastroplasty with transverse fundoplasty and total fundoplication. The approach is by a left thoracotomy. The esophagus is freed from beneath the aortic arch to the hiatus. A No. 50 Maloney bougie is passed orally into the stomach. A 30-mm linear stapler (TA 30) is applied to oppose the anterior and posterior walls of the stomach (A). The stomach is opened along the linear stapler on the fundus side (B). The gastrotomy is enlarged toward the fundus using a 7.5-cm gastrointestinal anastomosis stapler (C). Transverse closure of the fundus takes place using separate Connell-type sutures with 3-0 polyglycolic monofilament material (D, E). The widened fundus is then brought up to completely cover the transection line of the elongation gastroplasty (F, 1G). Once symmetrically positioned at the apex of the gastroplasty, the total fundoplication is completed (G). The anchoring sutures of the 3-cm fundoplication are fixed on the gastroplasty wall opposite to the transection line. The fundoplication is then reduced under the diaphragm (H), and 3 or 4 anchoring sutures maintain the repair in its abdominal position (I). The gastroplasty staple line is oriented on the left side (greater curvature), and the suture of the anterior and posterior fundoplication is on the right side (small curvature) $(\mathrm{J})$. 


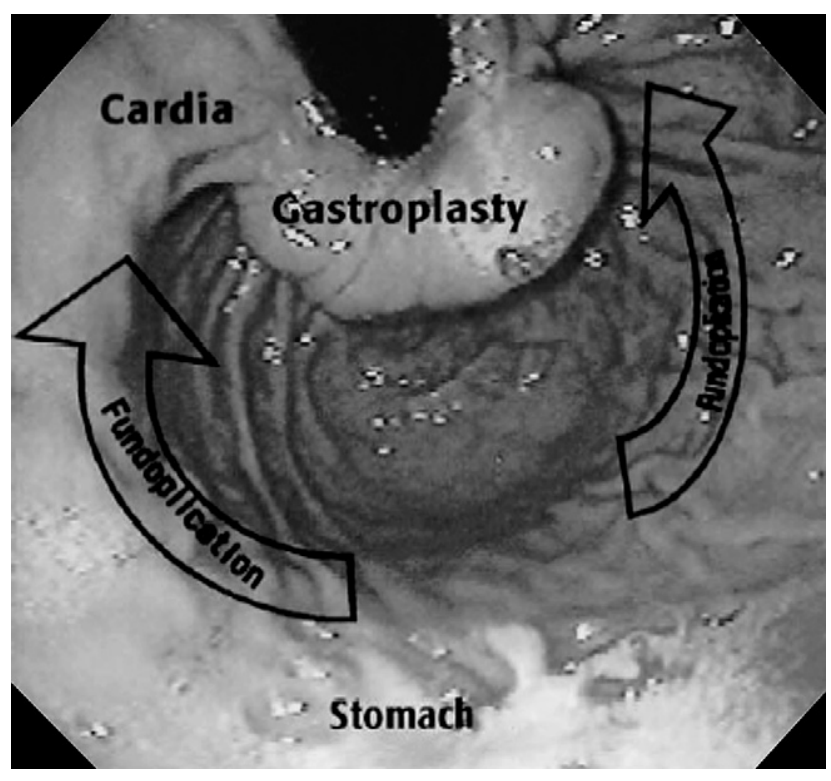

FIGURE 2. Endoscopic appearance of the fundoplication following a Jeyasingham gastroplasty. The wrap around the neoesophagus is comparable to the effect of a standard Nissen fundoplication.

from the intrasphincteric pressures to obtain the lower esophageal gradient existing between esophagus and stomach.

\section{Twenty-Four-Hour pH Recording}

A Sandhill ambulatory, $\mathrm{pH}$ recorder (Sandhill, Littleton, Colo) was used to register reflux events during 24-hour periods. The antimony electrode was placed $5 \mathrm{~cm}$ above the gastroesophageal junction, which had been identified manometrically. The total number of reflux episodes, the number of reflux episodes lasting more than 5 minutes, the number of minutes of reflux, and the percentage of time of exposure to acid were computed.

\section{Statistical Analysis}

Only patients with available functional assessment before and after operation were included in the statistical analysis to provide reliable pairwise comparison. Values are expressed as median and range or mean and standard deviation, as appropriate. Related dichotomous variables were analyzed by the McNemar test (2-tailed test). The Wilcoxon test was used for the comparison between paired continuous variables (preoperative and postoperative data).

\section{RESULTS}

\section{Operative Morbidity and Mortality}

No technical mishaps occurred during the operation. The mean duration of surgery was $319 \pm 69$ minutes. The mean blood loss was $432 \pm 300 \mathrm{~mL}$. There was no postoperative mortality. Six patients developed complications: cardiac arrhythmia $(n=2)$, deep venous thrombosis $(n=1)$, pericardial effusion $(n=2)$, and cholecystitis $(n=1)$. The mean hospital stay was 9.8 days (range 7-25).

\section{Patient Outcome}

Clinical follow-up was obtained in all patients. Two patients died from unrelated causes, 1 and 9 years after the operation, without complete reevaluation. One patient with cystic fibrosis refused to undergo full reassessment of function but accepted a radiologic control. One patient had no esophageal laboratory reevaluation. The follow-up ranged from 6 to 128 months (median, 105 months).

\section{Symptoms}

The effects of the operation on symptoms are summarized in Table 2. Globally, all symptoms improved significantly (preoperative, 26; postoperative, 5; $P<.001$ ). When used for primary repair, all preoperative complaints disappeared except a slow emptying sensation without frank dysphagia in 1 patient $(P=.002)$. If patients were reoperated for failed antireflux surgery, preoperative and postoperative symptoms were also significantly improved $(P=.004)$. However, more symptoms persisted postoperatively. No dilatations were required.

\section{Radiologic Evaluation}

Twenty-three of the 26 patients had radiologic reassessment of their repairs. Findings are summarized in Table 3. The gastroplasty stopped the gastroesophageal reflux (preoperative, 11; postoperative, $0 ; P=.002$ ). No significant stasis of the radiopaque material was observed above the repair. The fundoplication was considered intact in all patients. One patient who experienced previous failed antireflux surgery and who had a known diverticulum before the operation showed the same epiphrenic diverticulum after the gastroplasty and partial fundoplication.

\section{Endoscopy and Pathology}

Pre- and postoperative endoscopic assessments were available in 23 patients (Table 3). The fundoplication was considered intact in all patients. When quantified

TABLE 2. Symptoms and radiologic findings

\begin{tabular}{|c|c|c|c|c|c|c|c|c|c|}
\hline & \multicolumn{3}{|c|}{ Overall } & \multicolumn{3}{|c|}{ Primary surgery } & \multicolumn{3}{|c|}{ Redo surgery } \\
\hline & Preop & Postop & $\boldsymbol{P}$ & Preop & Postop & $\boldsymbol{P}$ & Preop & Postop & $P$ \\
\hline Any symptoms & 26 & 5 & $<.001$ & 12 & 1 & .002 & 14 & 4 & .004 \\
\hline Heartburn & 20 & 1 & $<.001$ & 11 & 0 & .002 & 9 & 1 & .013 \\
\hline Regurgitation & 16 & 4 & .001 & 9 & 0 & .007 & 7 & 4 & $>.2$ \\
\hline Dysphagia & 8 & 1 & .023 & 4 & 1 & $>.2$ & 4 & 0 & .13 \\
\hline Odynophagia & 5 & 1 & .13 & 2 & 0 & $>.2$ & 3 & 1 & $>.2$ \\
\hline Oropharyngeal symptoms & 6 & 1 & .073 & 4 & 0 & .13 & 2 & 1 & $>.2$ \\
\hline
\end{tabular}

Preop, Preoperatively; Postop, postoperatively. 
TABLE 3. Radiologic and endoscopic results

\begin{tabular}{|c|c|c|c|c|c|c|c|c|c|}
\hline & \multicolumn{3}{|c|}{ Overall $(n=23)$} & \multicolumn{3}{|c|}{ Primary surgery $(n=11)$} & \multicolumn{3}{|c|}{ Redo surgery $(\mathrm{n}=12)$} \\
\hline & Preop & Postop & $\boldsymbol{P}$ & Preop & Postop & $\boldsymbol{P}$ & Preop & Postop & $\boldsymbol{P}$ \\
\hline Hiatal hernia (type $1 / 2 / 3$ ) & $17(11 / 2 / 4)$ & 0 & $<.001$ & $9(8 / 0 / 2)$ & 0 & .007 & $8(3 / 2 / 2)$ & 0 & .013 \\
\hline Reflux & 11 & 0 & .002 & 8 & 0 & .013 & 3 & 0 & $>.2$ \\
\hline Stasis & 2 & 0 & $>.2$ & 1 & 0 & $>.2$ & 1 & 0 & $>.2$ \\
\hline Mucosal damage & 4 & 0 & .13 & 0 & 0 & - & 4 & 0 & .13 \\
\hline MUSE $\geq 1$ & 21 & 18 & $>.2$ & 10 & 8 & $>.2$ & 11 & 10 & $>.2$ \\
\hline Metaplasia $\geq 1$ & 20 & 18 & & 9 & 8 & & 11 & 10 & \\
\hline Ulcer $\geq 1$ & 5 & 0 & & 2 & 0 & & 3 & 0 & \\
\hline Stenosis $\geq 1$ & 3 & 0 & & 3 & 0 & & 0 & 0 & \\
\hline Erosion $\geq 1$ & 13 & 0 & & 7 & 0 & & 6 & 0 & \\
\hline Quantification MUSE & $3.1 \pm 0.9$ & $1.5 \pm 0.7$ & $<.001$ & $3 \pm 1$ & $1.4 \pm 0.8$ & .02 & $3 \pm 0.9$ & $1.6 \pm 0.7$ & .02 \\
\hline Length of metaplasia (cm) & $4.8 \pm 3$ & $4.2 \pm 3$ & .058 & $5.5 \pm 4$ & $4.6 \pm 4$ & .064 & $4.1 \pm 3$ & $3.8 \pm 2$ & $>.2$ \\
\hline
\end{tabular}

Data are expressed in number of patients, mean and standard deviation. Preop, Preoperatively; Postop, postoperatively.

preoperatively, mucosal damage was reduced significantly after the repair (preoperative, $3.1 \pm 0.9$; postoperative, 1.5 $\pm 0.7 ; P<.001)$. For those patients who had a primary repair, the decrease in mucosal lesions from $3 \pm 1$ to $1.4 \pm$ 0.8 after the repair was significant $(P=.02)$. Preoperative values of patients undergoing a reoperation $(3 \pm 0.9)$ were also reduced significantly after the operation $(1.6 \pm 0.7$; $P=.02)$. When a columnar-lined esophagus was present before surgery, it persisted after the repair $(P>.2)$. The length of the metaplastic mucosa remained unchanged after the operation $(P=.058)$. Strictures and ulcers were all controlled. Erosions were reduced after surgery in the total cohort $(P<.001)$, after primary surgery $(P=.023)$, and after reoperations $(P=.041)$.

Twenty of the 23 patients $(87 \%)$ had intestinal metaplasia on preoperative biopsies ( 9 before their primary surgery, 11 before their reoperation). Eighteen of the 23 reassessed patients $(78 \%)$ had columnar-lined mucosa on their biopsies postoperatively ( 8 after primary surgery, 10 after redo; $P>$.2). Acute mucosal damage (ulceration, erosion) healed in all patients $(P=.13)$. All strictures were improved and remained stable.

\section{Manometry}

Twenty patients underwent pre- and postoperative manometric evaluation. Table 4 details the values before and after the operation. There was a significant loss of peristalsis in both the proximal and in the distal esophagus after the operation. Peak contraction pressures remained unchanged. Significant improvement was observed for the absolute resting pressures of the lower sphincter $(P=.015)$, its closing pressures $(P=.009)$, and the identified gradient between esophagus and stomach $(P=.003)$. This, however, had a cost in the relaxation capacity of the high-pressure zone, which was decreased from a preoperative value of $100 \%$ to a postoperative relaxation of $90 \%(P=.001)$. These global changes were similar when the patients had the operation as primary repair. The functional changes were less evident when patients were reoperated.

TABLE 4. Manometric results

\begin{tabular}{|c|c|c|c|c|c|c|c|c|c|}
\hline & \multicolumn{3}{|c|}{ Overall } & \multicolumn{3}{|c|}{ Primary surgery } & \multicolumn{3}{|c|}{ Redo surgery } \\
\hline & Preop & Postop & $\boldsymbol{P}$ & Preop & Postop & $P$ & Preop & Postop & $P$ \\
\hline \multicolumn{10}{|l|}{ Proximal esophageal body } \\
\hline Resting pressure (mm Hg) & $8(3-26)$ & $8.3(3-36)$ & $>.2$ & $7(3-26)$ & $7(3-36)$ & $>.2$ & $9(3-14)$ & $8.7(3-24)$ & $>.2$ \\
\hline Peak pressure $(\mathrm{mm} \mathrm{Hg})$ & $53.5(13-86)$ & $44(19-107)$ & .18 & $46(33-86)$ & $54(29-107)$ & .1 & $54(34-83)$ & $41(19-95)$ & $>.2$ \\
\hline Primary waves $(\%)$ & $100(50-100)$ & $90(50-100)$ & .07 & $100(70-100)$ & $100(66-100)$ & $>.2$ & $100(50-100)$ & $80(50-100)$ & 0.1 \\
\hline \multicolumn{10}{|l|}{ Distal esophageal body } \\
\hline Resting pressure (mm Hg) & $6.3(3-15)$ & $6.3(2-37)$ & $>.2$ & $5(3-10)$ & $5(3-9)$ & $>.2$ & $7(3-15)$ & $7.3(2-37)$ & $>.2$ \\
\hline Peak pressure $(\mathrm{mm} \mathrm{Hg})$ & $47(17-82)$ & $36(20-129)$ & $>.2$ & $40(27-82)$ & $39(28-129)$ & .15 & $51(17-98)$ & $33(20-58)$ & .046 \\
\hline Primary waves $(\%)$ & $100(50-100)$ & $90(60-100)$ & .016 & $100(50-100)$ & $100(60-100)$ & $>.2$ & $100(70-100)$ & $85(60-100)$ & .01 \\
\hline \multicolumn{10}{|l|}{ Lower esophageal sphincter } \\
\hline Resting pressure (mm Hg) & $19(12-38)$ & $26(14-34)$ & .015 & $15(12-31)$ & $27(16-34)$ & .003 & $21(12-38)$ & $25.5(14-34)$ & $>.2$ \\
\hline Gradient pressure $(\mathrm{mm} \mathrm{Hg})$ & $7.5(6-25)$ & $15(4-22)$ & .003 & $6(0-12)$ & $16(12-21)$ & .003 & $8(1-25)$ & $14(4-22)$ & .13 \\
\hline Closing pressure (mm Hg) & $28.6(18-70)$ & $39.5(26-49)$ & .009 & $22(18-33)$ & $39(26-49)$ & .003 & $34(28-70)$ & $40(28-48)$ & $>.2$ \\
\hline Relaxation (\%) & $100(40-100)$ & $90(33-100)$ & .001 & $100(100-100)$ & $80(33-100)$ & .005 & $100(40-100)$ & $100(40-100)$ & .03 \\
\hline
\end{tabular}

Data are expressed in median and range. Preop, Preoperatively; Postop, postoperatively. 
TABLE 5. pH monitoring results

\begin{tabular}{|c|c|c|c|c|c|c|c|c|c|}
\hline & \multicolumn{3}{|c|}{ Overall } & \multicolumn{3}{|c|}{ Primary surgery } & \multicolumn{3}{|c|}{ Redo surgery } \\
\hline & Preop & Postop & $P$ & Preop & Postop & $P$ & Preop & Postop & $P$ \\
\hline Total No. of episodes & $136(54-300)$ & $17(3-296)$ & .004 & $127(44-271)$ & $30(6-296)$ & .04 & $138(68-300)$ & $10(3-197)$ & .019 \\
\hline Episodes $>5 \mathrm{~min}$ & $8(0-27)$ & $6(0-17)$ & $<.001$ & $3(0-27)$ & $0(0-17)$ & .013 & $9(0-20)$ & $0.5(0-10)$ & .014 \\
\hline Minutes of exposure & $165(8-698)$ & $11(0-384)$ & .0015 & $110(18-698)$ & $11(0-369)$ & .025 & $213(42-384)$ & $20(2-384)$ & .007 \\
\hline Time $\%$ of exposure & $17(1-67)$ & $1(0-28)$ & $<.001$ & $14(1-67)$ & $1(0-27)$ & .005 & $20(3-33)$ & $1(0-28)$ & .008 \\
\hline
\end{tabular}

Data are expressed in median and range. Preop, Preoperatively; Postop, postoperatively.

\section{Twenty-Four-Hour pH Recordings}

A 24-hour $\mathrm{pH}$ recording results were available pre- and postoperatively in 19 patients. Details of the $\mathrm{pH}$ recordings are given in Table 5. The number of reflux episodes, the number of episodes lasting more than 5 minutes, the minutes of acid exposure, and the percentage of exposure time to acid were all improved after the operation. These changes were similar whether the patients had the operation as a primary repair or after a failed previous fundoplication. Four patients still showed acid exposure 1 year after their operation (1 patient after primary repair and 3 patients after redo surgery). All 4 patients had a Barrett's esophagus with fundic and specialized epithelium.

\section{DISCUSSION}

In 1984, Reilly and Jeyasingham ${ }^{16}$ initially reported a 3-cm elongation gastroplasty with a transverse widening of the fundus. They suggested that with this modification of the Pearson gastroplasty a complete fundoplication was made easier and provided healthy tissue around the gastroplasty. In 1998, Jeyasingham and colleagues ${ }^{17}$ reported their 10-year results in 58 patients. Fifteen of them $(26 \%)$ had had a previous failed antireflux operation. The repair allowed for a good control of acid exposure and relief of symptoms. A durable reconstruction with no long-term recurrence was achieved despite the number of failed previous repairs.

Jeyasingham's group reported a postoperative mortality similar to what has been reported with the other elongation gastroplasties. Three of their patients (5\%) died, one of complications related to the technique. Pearson and associates ${ }^{3}$ reported 2 deaths from cardiopulmonary complications in 430 patients having a Collis-Belsey gastroplasty. Orringer and Sloan ${ }^{6}$ and Trastek and colleagues ${ }^{13}$ also reported low mortality in their respective variations of the total fundoplication around the neoesophagus $(2 \%-3 \%)$. Other groups reported no mortality with either the cut or the uncut Collis-Nissen repair. ${ }^{14,15,19}$ In the present study in which over $50 \%$ of patients were having reoperation, none of the patients died and the morbidity was minimal.

Reoperation for recurrent hernias and failed reflux control is always a challenge. ${ }^{20}$ Despite the notion that reoperation can be undertaken using minimally invasive techniques, we have used exclusively the open thoracic approach for these problems. Whatever the surgical approach (open or laparoscopy), redo surgery can result in significant morbidity ranging from $1 \%$ to $30 \%$ and in mortality ranging from $0 \%$ to $4 \%{ }^{21-26}$ After mobilization of the distal esophagus and proximal stomach, the freed and unwrapped fundic tissue is not always of the best quality for a repair, and intraoperative perforation of the stomach or esophagus may occur in between $10 \%$ and $30 \%$ of cases. ${ }^{22-25}$

When reviewing their experience with the elongation gastroplasty, Orringer and Sloan ${ }^{6}$ emphasized the difficulties of reoperation when reporting 1 perforation and 1 gastroplasty necrosis. If the gastroplasty can be completed satisfactorily, a definitive advantage of the Jeyasingham repair is the fact it provides healthy greater curvature tissue after opening the stomach and trimming the dissected fundus. The transverse closure of the fundus at the distal end of the gastroplasty implies an inverted " $\mathrm{T}$ " anastomosis, which definitely needs protection by being wrapped in healthy gastric tissue. In the present series, it has not resulted in morbidity for either the gastroplasty or the modified fundic wrap. Although we have used that repair as a primary procedure in 12 patients, we consider it a more complex reconstruction than the 2 other Collis-Nissen variations in patients who were not operated previously. We feel it should be reserved for patients in need of a reoperation, especially if the new repair would be unsatisfactory or possibly end in the resection of the esophagogastric junction.

Our clinical assessment shows an excellent relief of symptoms over time for operated patients. One of our 26 patients (4\%) reported heartburn after the operation, a prevalence similar to that observed by Jeyasingham and colleagues. ${ }^{17}$ In comparison, $4 \%$ of patients having Collis-Belsey gastrostomy ${ }^{3}$ remain symptomatic, and less than $2 \%$ of patients with a cut Collis-Nissen gastroplasty report symptoms. ${ }^{6,15}$ When an uncut Collis-Nissen gastroplasty is fashioned, it provides an excellent relief for heartburn but results in slower emptying, and episodes of dysphagia are reported more frequently $(11 \%){ }^{14}$

Dysphagia was present in 1 of 58 patients in Jeyasingham and colleagues, ${ }^{17}$ series. No frank postoperative dysphagia was reported by the operated patients in our group. One of them reported a slow emptying sensation. Previous series of patients with either Collis-Belsey operations or CollisNissen repairs reported a $6 \%$ to $17 \%$ incidence of dysphagia $^{6,14,15,27}$ with dilatations required for as many as $11 \%$ of patients. ${ }^{14}$ The esophageal wall pathology may have varied significantly in these reports. 
The long-term recurrence rate with an elongation gastroplasty is estimated to vary from $1 \%$ to $10 \%$ with open approach $^{8,9,13-15,28,29}$ and from $0.5 \%$ to $4.5 \%$ when managed laparoscopically. ${ }^{21,30}$ All of the Jeyasingham repairs in this series are considered intact after 9-year median follow-up. Similar results were reported by Jeyasingham and colleagues ${ }^{17}$ with a follow-up of 48 months.

Just as in Jeyasingham and colleagues ${ }^{17}$ report, we observed complete regression of all acute esophagitis lesions in the present cohort. The metaplastic columnar-lined esophagus, however, remained unchanged. Trastek and colleagues ${ }^{13}$ and Pera and associates ${ }^{14}$ reported similar healing rates without regression of the Barrett's mucosa. Chen and coworkers ${ }^{15}$ documented the disappearance of all active esophagitis lesions without observing any changes in the columnar-lined esophagus. In contrast, Jobe and colleagues ${ }^{27}$ reported that $36 \%$ of their patients after laparoscopic Collis-Nissen still revealed active esophagitis with persistence of oxyntic mucosa in all of them. Persistence of the metaplastic mucosa suggests the need for continued endoscopic and histologic surveillance despite a successful repair.

The functional results of elongation gastroplasties have been well documented. When a partial fundoplication (Collis-Belsey) is added, the LES gradient is increased by $2.4 \mathrm{~mm} \mathrm{Hg}{ }^{4}$ By creating a total fundoplication (CollisNissen), the distal high-pressure zone is increased by 4.2 to $9 \mathrm{~mm} \mathrm{Hg} .{ }^{6,15,27}$ If the gastroplasty is made with the uncut technique and a total fundoplication is created by a wrap of both the anterior and posterior fundic walls, the LES gradient is increased by $6.3 \mathrm{~mm} \mathrm{Hg},{ }^{14}$ and as for a total fundoplication, this is at the cost of a reduced relaxation. The Jeyasingham modification to the technique produces similar functional improvements. The LES shows significant pressure and gradient increases. In proximal as well as in the distal esophagus, a discrete loss of propulsion is observed, mostly in patients undergoing a reoperation. Contraction strength is preserved. Similar changes were observed by Jeyasingham and colleagues ${ }^{17}$ in their 28 patients having manometric reassessment.

The main goals of the elongation gastroplasty repairs are a tension-free hernia correction with the control of both pathologic reflux exposure and esophageal mucosal damage. In the early reports of Orringer and Sloan ${ }^{20}$ and Henderson, ${ }^{4}$ persistent acid exposure was observed in $30 \%$ to $44 \%$ of patients. After opting to create a total fundoplication around the neoesophagus, acid exposure was still observed in 1/19 patients in Orringer and Sloan's experience. ${ }^{6}$ Pera and colleagues ${ }^{14}$ and Chen and associates ${ }^{15}$ found that a significant proportion of their patients were still exposed to acid secretions. Explanations suggested for this observation were (1) an extended columnar-lined esophagus in a high proportion of patients, with possible acid production by gastric metaplasia cells; (2) persisting reflux from the stomach; (3) acid secretion by the neoesophagus; and (4) decaying food particles in the esophageal lumen. Jobe and colleagues ${ }^{27}$ found that $50 \%$ of their patients after a laparoscopic Collis gastroplasty showed abnormal acid exposure. Positive Congo red staining was documented, indicating the presence of actively secreting gastric mucosa in the neoesophagus. ${ }^{27}$

In this series, 4 of 20 reassessed patients are still exposed to an abnormal acid exposure in their esophagus mainly after a previous failed repair. Because $87 \%$ of the patients had a documented columnar-lined esophagus, the same argumentation can be made to explain this abnormal exposure. In their 31 patients reassessed by 24 hours pH-recording, Jeyasingham and colleagues ${ }^{17}$ found no significant reflux following the operation. Some of the technical aspects when creating an elongation gastroplasty may be influential, such as a partial versus a total fundic wrap. Henderson ${ }^{4}$ and Orringer and Sloan ${ }^{6}$ created their wrap with the remaining gastric fundus, in which the base is attached to the stomach and the tip is wrapped around the gastroplasty. The effect might be compared with that of an inverted funnel with more tension exerted proximally than distally. When making an uncut gastroplasty, the $3-\mathrm{cm}$ wrap with both walls of the fundus creates a symmetrical and very competent gastroplasty. The Jeyasingham modification to the fundus allows the creation of a fundoplication very similar technically and at endoscopy to a standard Nissen repair.

In summary, although this observation is retrospective with a limited number of patients, it offers objective functional reevaluation of this operation in most patients. Our results, as those of Jeyasingham and colleagues, ${ }^{17}$ were obtained after an open thoracic approach. The operation provides a reliable anatomic correction over time for conditions known to produce a shortened esophagus. It offers a tension-free repair in an abnormal position and allows for a significant reduction of reflux symptoms. The LES gradient is restored and remains stable over time. Acid reflux exposure is significantly reduced and acute mucosal damage heals over time. Intestinal metaplasia remains unchanged. Despite the absence of morbidity related to the operation, the technical realization of the repair is more complex than for the other 2 varieties of Collis-Nissen operations. For these reasons, for a number of years, we have reserved this approach for recurrent reflux or hernia problems.

\section{References}

1. Pearson FG. Gastroplasty. In: Pearson FG, Deslauriers J, Ginsberg RJ, et al., eds. Esophageal Surgery. 1st ed. New York: Churchill Livingston; 1995. P.339-59.

2. Collis JL. An operation for hiatus hernia with short esophagus. J Thorac Cardiovasc Surg. 1957;34:768-73.

3. Pearson FG, Langer B, Henderson RD. Gastroplasty and Belsey hiatus repair: an operation for the management of peptic stricture with acquired short esophagus. J Thorac Cardiovasc Surg. 1971;61:50-63.

4. Henderson RD. Reflux control following gastroplasty. Ann Thorac Surg. 1977; 24:206-14.

5. Henderson RD, Marryatt G. Total fundoplication gastroplasty. J Thorac Cardiovasc Surg. 1983;85:81-7.

6. Orringer MB, Sloan H. Combined Collis-Nissen reconstruction of the esophagogastric junction. Ann Thorac Surg. 1978;25:16-21. 
7. Bingham JAW. Evolution and early results of constructing an antireflux valve in the stomach. Proc R Soc Med. 1974;67:4-8.

8. Bingham JAW. Hiatus hernia repair combined with the construction of an anti-reflux valve in the stomach. Br J Surg. 1977;64:460-5.

9. Demos NJ, Smith N, Williams D. New gastroplasty for strictured short esophagus. N Y State J Med. 1975;75:57-9.

10. Demos NJ. Stapled, uncut gastroplasty for hiatal hernia: 12-year follow-up. Ann Thorac Surg. 1984;38:393-400.

11. Evangelist FA, Taylor FH, Alford JD. The modified Collis-Nissen operation for control of gastroesophageal reflux. Ann Thorac Surg. 1978;26:107-11.

12. Paris F, Tomais-Ridocci M, Benages A, et al. Gastroplasty with partial or total plication for gastroesophageal reflux: manometric and $\mathrm{pH}$-metric postoperative studies. Ann Thorac Surg. 1981;33:540-8.

13. Trastek VF, Deschamps C, Allen MS, Miller DL, Pairolero PC, Thompson AM. Uncut Collis-Nissen fundoplication: learning curve and long-term results. Ann Thorac Surg. 1998;66:1739-44.

14. Pera M, Deschamps C, Taillefer R, Duranceau A. Uncut Collis-Nissen gastroplasty: early functional results. Ann Thorac Surg. 1995;60:915-20.

15. Chen LQ, Nastos D, Hu CY, Chughtai TS, Taillefer R, Ferraro P, et al. Results of the Collis-Nissen gastroplasty in patients with Barrett's esophagus. Ann Thorac Surg. 1999;68:1014-20.

16. Reilly KM, Jeyasingham K. A modified Pearson gastroplasty. Thorax. 1984;39: $67-9$

17. Jeyasingham K, Bhatnagar NK, Peppas G, Payne HR. A continuous 10-year assessment of the results of surgery for shortened esophagus. In: Nabeya K, Hanaoka T, Nogami H, eds. Recent advances in diseases of the esophagus. Tokyo: Springer-Verlag; 1998. P.84-90.

18. Armstrong D, Monnier PH, Nicolet M, et al. Endoscopic assessment of oesophagitis. Gullet. 1991;1:63-7.

19. Richardson JD, Richardson RL. Collis-Nissen gastroplasty for shortened esophagus: long-term evaluation. Ann Surg. 1998;227:735-40.
20. Orringer MB, Sloan H. Complications and failings of the combined Collis-Belsey operation. J Thorac Cardiovasc Surg. 1977;74:726-35.

21. Whitson BA, Hoang CD, Boettcher AK, Dahlberg PS, Andrade RS, Maddaus MA. Wedge gastroplasty and reinforced crural repair: important components of laparoscopic giant or recurrent hiatal hernia repair. J Thorac Cardiovasc Surg. 2006;132:1196-202.

22. Iqbal A, Awad Z, Simkins J, Shah R, Haider M, Salinas V, et al. Repair of 104 failed anti-reflux operations. Ann Surg. 2006;244:42-51.

23. Furnée EJ, Draaisma WA, Broeders IA, Smout AJ, Gooszen HG. Surgical reintervention after antireflux surgery for gastroesophageal reflux disease: a prospective cohort study in 130 patients. Arch Surg. 2008;143:267-74.

24. Granderath FA, Kamolz T, Schweiger UM, Pointner R. Long-term follow-up after laparoscopic refundoplication for failed antireflux surgery: quality of life, symptomatic outcome, and patient satisfaction. J Gastrointest Surg. 2002;6: 812-8.

25. Gadenstätter M, Hagen JA, DeMeester TR, Ritter MP, Peters JH, Mason RJ, et al. Esophagectomy for unsuccessful antireflux operations. J Thorac Cardiovasc Surg. 1998;115:296-300.

26. Avaro JP, D'Journo XB, Trousse D, Ouattara MA, Doddoli C, Giudicelli R, et al. Long-term results of redo gastro-esophageal reflux disease surgery. Eur J Cardiothorac Surg. 2008;33:1091-5.

27. Jobe BA, Horvath KD, Swanstrom LL. Postoperative function following laparoscopic Collis gastroplasty for shortened esophagus. Arch Surg. 1998;133:867-74

28. Maziak DE, Todd TR, Pearson FG. Massive hiatus hernia: evaluation and surgical management. J Thorac Cardiovasc Surg. 1998;115:53-60.

29. Patel HJ, Tan BB, Yee J, Orringer MB, Iannettoni MD. A 25-year experience with open primary transthoracic repair of paraesophageal hiatal hernia. J Thorac Cardiovasc Surg. 2004;127:843-9.

30. Pierre AF, Luketich JD, Fernando HC, Christie NA, Buenaventura PO, Litle VR, et al. Results of laparoscopic repair of giant paraesophageal hernias: 200 consecutive patients. Ann Thorac Surg. 2002;74:1909-15. 